\title{
Polisemia
}

\section{CHAMANISMO Y LOS EJERCICIOS ESPIRITUALES EN LA GRECIA CLÁSICA}

Por Ginna Fernanda García Aguilar'

\section{Resumen:}

$E$ I texto pretende diferenciar claramente los ejercicios espirituales propios de las escuelas filosóficas griegas y las prácticas chamánicas. Para la autora la comparación entre ambos fenómenos constituye un reduccionismo en el que incurren algunos autores. El sentido de los ejercicios espirituales en la antigua Grecia consistía en la transformación de sí mismo; en una práctica pedagógica orientada a formar mejores ciudadanos dentro de un tipo de formación política y de praxis social determinada. Aunque los rituales chamánicos también están ligados al funcionamiento político de la comunidad, éstos se basan en el equilibrio entre los dioses y los hombres y se anclan más en el terreno de la búsqueda de conocimientos que operen como dispositivos de orden simbólico de las actividades de la comunidad.

\section{Palabras Claves:}

Chamanismo, ejercicios espirituales, filósofo, chamán, sí mismo, comunidad

\section{SHAMANISM AND THE SPIRITUAL EXERCISES OF THE ANCIENT GREECE}

\section{Abstract:}

The authortries to differentiateclearly the spiritualexercises of the Greekphilosophical schools from the shamanic practices. In the author's opinion the comparison between the two phenomena is a reductionism in which incurred some researchers. The sense of the spiritual exercises in ancient Greece was the transformation of the subject by himself; a practice oriented to educate better citizens in a specific kind of political structure and social praxis. Though shamanistic rituals are connected with the operation of the political community, too, these are based on a balance between gods and human beings and they are aimed to search knowledge that operate as a device of symbolic order for the community's activities.

\section{Key words:}

Shamanism, spiritual exercises, philosopher, shaman, itself, community 
Algunos autores suelen comparar los ejercicios espirituales propios de las escuelas filosóficas griegas con las prácticas chamánicas, otros pretenden llegar hasta la génesis de aquellos, en estas últimas. Este escritointentará mostrar que tal comparación constituye un reduccionismo y que los ejercicios espirituales no corresponden a la misma categoría que los trances chamánicos. Este texto tratará en un primer momento las especificidades de la ciudad clásica griega y precisará tanto el contenido como el sentido de los ejercicios espirituales en este contexto. Seguidamente, se acotarán las circunstancias sociales que llenan de contenido las prácticas chamánicas. Finalmente, se hablará de la diferencia entre el tipo de conocimiento que existe en los ejercicios filosóficos y estas últimas. Importa comprender que el sentido de los ejercicios espirituales en los antiguos es el de la transformación de sí, mientras que el chamanismo es indisociable del funcionamiento social, político, económico y religioso de la comunidad en su totalidad.

También es necesario hacer una precisión antes de continuar. Esta no es una investigación exhaustiva sobre la filosofía antigua y por ello los argumentos que desarrollará este texto pertenecen a la antropología y la filosofía política. Pierre Hadot en su texto ¿Qué es la filosofía antigua? reconstruye una serie de explicaciones que buscan develar la génesis de los ejercicios espirituales (askesis, meletê) presentes en el modo de vida de los filósofos antiguos. Frente a la dificultad de acceder a la realidad de la Grecia antigua, muchas hipótesis han sido propuestas a la hora de explicar, por ejemplo, las técnicas de control de la respiración.
J. P. Vernant ${ }^{2}$ clasifica estas técnicas como parte de la tradición chamánica. Hadot recoge también los planteamientos de $\mathrm{K}$. Meuli ${ }^{3}$ y E. R Dodds ${ }^{4}$, quienes a través del chamanismo, pretenden explicar la génesis de las representaciones de los filósofos griegos sobre el alma, sobre la relación entre el alma y el cuerpo, además de los viajes del alma. Eliade ${ }^{5}$, de manera similar, propone que el origen de las técnicas de éxtasis de los griegos se encuentra en el chamanismo.

Hadot se muestra en desacuerdo con estas aproximaciones y propone dos razones para argumentar su parecer. La primera razón sostiene que

Los ejercicios espirituales que nos interesan ya nada tienen que ver con los rituales chamánicos y responden al contrario a una rigurosa necesidad de control racional, necesidad que surge para nosotros con los primeros pensadores de Grecia, y con los sofistas y Sócrates. ${ }^{6}$

La segunda es la siguiente: "me parece que los historiadores de la filosofía tienen del chamanismo una representación muy idealizada y espiritualizada, lo que les permite ver chamanismo por todas partes". Seguidamente, Hadot refuta la tesis de H. Joly, quién afirma que Sócrates puede ser considerado como un chamán porque se aislaba para meditar y cuando lo hacía llegaba a permanecer inmóvil por una gran cantidad de tiempo.

Para H. Joly el hecho de que Sócrates se mantuviera alejado y permaneciera inmóvil para meditar, el hecho de que "aplicaba su espíritu" a sí mismo, demuestra que recurría a técnicas muy conocidas del control de la respiración [...] por mi parte, considero que, si se desea meditar tranquilamente, es necesario permanecer

2. Cf. Vernant, J. P. (1971) Myhte et pensée chez les Grecs, París. Vol. I, p.114.

3. Cf. Meuli, K. (1935) Scythica, en Hermes, Basilea-Darmstadt. Vol. 70, pp. 137 y ss.

4. Cf. Eliade, M. (1960) El chamanismo y las técnicas arcaicas del éxtasis, Buenos Aires: Fondo de la Cultura Económica.

5. Cf. Doods, E. (1986) Los griegos y lo irracional. Madrid: Alianza.

6. Hadot, P. (1988) ¿Qué es la filosofía antigua? México: Fondo de la Cultura Económica, p. 200.

7. Ibíd.

8. Cf. Joly, H. (1974) Le renversement platonicien, París : Vrin. 
inmóvil y en silencio y que esta conducta nada tiene que ver con el retraimiento del chamán. ${ }^{9}$

Hadot subraya que Eliade y Dodds representan el chamanismo como el poder de un individuo para transformar voluntariamente la relación que mantiene con su alma y su cuerpo. Esta afirmación implica una serie de preguntas. Es pertinente en un primer momento preguntarse ¿qué implica la noción de individuo?, ¿de qué individuo se está hablando?

En este momento es plausible apelar al trabajo de Michel Foucault quien sitúa al individuo dentro de una red de relaciones de poder. Poder e individuo son, de esta manera, co-constitutivos. La red de relaciones de poder funciona en una micro-escala, es decir, en el ámbito del individuo. La transformación de sí, la empresa ética de cambio interior se articula y se llena de contenido en espacios pedagógicos, políticos, sociales.

El siguiente acápite de este artículo estará dedicado a precisar el sentido de los ejercicios espirituales efectuados por los filósofos de la Grecia Antigua. Estos ejercicios han sido propuestos a los individuos "para fijar su identidad, mantenerla o transformarla en función de cierto número de fines, y todo ello gracias a las relaciones de dominio de sí sobre uno mismo o de conocimiento de uno por sí mismo". ${ }^{10}$

$* * * * * * *$

En La inquietud de sí, del tercer tomo de la Historia de la sexualidad, Michel Foucault hace un estudio detallado de las prácticas de individualización en la Grecia Antigua.
Veamos una definición de proceso de individualización con el fin de aclarar esta categoría de análisis:

La actitud individualista, caracterizada por el valor absoluto que se atribuye al individuo en su singularidad, y por el grado de independencia que se le concede respecto del grupo al que pertenece 0 de las instituciones de las que depende; la valorización de la vida privada, es decir la importancia reconocida de las relaciones familiares, a las formas de actividad doméstica y al campo de intereses patrimoniales; finalmente la intensidad de las relaciones con uno mismo, es decir las formas en las que se ve uno llamado a tomarse a sí mismo como objeto de conocimiento y campo de acción, a fin de transformarse, de corregirse, de purificarse, de construir la propia salvación. ${ }^{11}$

En estas prácticas es posible buscar la marca del proceso de individualización occidental. La historia de la sexualidad plantea un trabajo de ontología histórica desde la pregunta por "la relación ética por medio de la cual nos constituimos como sujetos de acción moral".12

Foucault encuentra en el Alcibíades de Platón la relación entre "conocerse a sí mismo y "ocuparse de sí mismo". ${ }^{13}$ El "arte de la existencia" está dominado por el principio de "cuidar de uno mismo". El cuidado de sí toma la forma de una actitud, una manera de comportarse. La inquietud de sí funda la necesidad, gobierna el desarrollo y organiza la práctica de los cuidados de sí. Ambas tecnologías ${ }^{14}$ constituyen un modo de conocimiento, llevan a la elaboración de un saber y cobran sentido en la actividad política, la pedagogía y en la práctica de una vida filosófica.

9. Hadot, P. (1988) Op. cit., p. 202.

10. Foucault, M. (1999) Subjetividad y verdad, en Estética, Ética y Hermenéutica Obras esenciales III, Barcelona: Ediciones Paidós, p. 255.

11. Cf. Foucault, M. La inquietud de sí, en Historia de la sexualidad, Tomo III, México: Fondo de la Cultura Económica, p. 41.

12. Foucault, M. (1990) Tecnologías del yo y otros textos afines, México: Paidós, p. 25.

13. Ibíd., p. 38.

14. Tecnología se refiere a los dispositivos utilizados por el hombre para entenderse a sí mismo. Foucault distingue cuatro, a saber: "1. Tecnologías de producción, que nos permiten producir, transformar o manipular cosas; 2 . Tecnologías de sistemas de sistemas de signos, que nos permiten utilizar signos, sentidos, símbolos o significaciones; 3.Tecnologías de poder, que determinan la conducta de los individuos, los someten a ciertos tipo de fines o dominación, y consisten en una objetivacion del sujeto; 4 . Tecnologías del yo, que permiten a los individuos efectuar, por cuenta propia o con la ayuda de otros, cierto número de operaciones sobre su cuerpo y su alma, pensamientos conducta o cualquier forma de ser, obteniendo así una transformación de sí mismos con el fin de alcanzar cierto estado de felicidad, pureza, sabiduría o inmortalidad" Ibíd., p. 48. 
Tanto en Grecia como en la cultura helénica se efectúan prácticas y ejercicios espirituales cuyo fin es la construcción de discursos verdaderos y razonables lógoi. Estos discursos permiten conjurar temores, enfrentar ideas de desgracia. Los estoicos y los epicúreos proponen ejercicios de memorización y apropiación de los discursos verdaderos, lo que requiere desarrollar un trabajo sobre sí que implica: una buena actitud de escucha, desarrollar ejercicios de escritura y realizar auto-exámenes de manera frecuente. Foucault subraya que estos discursos verdaderos, necesarios e indispensables conciernen a la relación entre el sujeto y el mundo, al sujeto y su lugar en el orden de la naturaleza y a la dependencia o independencia del sujeto respecto a los acontecimientos. ${ }^{15}$

Ejercicios que implican periodos de prueba voluntarios -ayuno, experimentación de la pobreza- , o que implican el control de las representaciones que provienen del pensamiento, tanto como ejercicios de meditación sobre la muerte tienen como finalidad "establecer y someter a prueba la independencia del individuo con respecto al mundo exterior".16

Por su parte, Hadot señala que en la República Platón elogiaba un modo de vida pitagórico. Dentro de una república, es decir, dentro de una formación política precisa, se hace pertinente hablar de individuo, de ejercicios espirituales y de técnicas de transformación de sí, de la posibilidad misma de pensar un sí, de pensarse (acentuando el pronombre reflexivo).

"El precepto: ocuparse de uno mismo era, para los griegos, uno de los principales principios de las ciudades, una de las reglas más importantes para la conducta social y personal y para el arte de la vida".17 Además, en tanto ciudadano, la filiación política supone la centralización política estatal.
Esto quiere decir que se pueden detectar cierta unificación y cierta canalización del poder dentro de un aparato institucional. Los griegos especulan incluso acerca de la naturaleza, de la deontología de esta institución. Bien sea una oligarquía o una democracia, aparece una institución política que se muestra mediadora entre los ciudadanos y el ejercicio del poder.

En síntesis, los ejercicios espirituales de la Grecia arcaica -y del periodo helénico- se enraízan en un proceso de producción de individuos, en un tipo de formación política y de praxis social determinada. Estos ejercicios son considerados como deber y como técnica cuya importancia apela a terrenos como la pedagogía, la política y la moral.

Si bien la institución chamánica también está anclada al terreno de lo político, dentro de ella no sería posible pensar una práctica pedagógica que busque construir mejores ciudadanos. El lugar de lo político toma, entonces, otras características, así como lo hace el balance entre sujeto y colectividad.

$* * * * * * * * * * * *$

En este contexto es difícil hablar de la existencia de una empresa de transformación de sí por medio de técnicas y ejercicios espirituales. Los rituales de toma de yagé (ayahuasca) o de retiro y aislamiento son rituales de reconocimiento mutuo, de creación y recreación de la comunidad a nivel simbólico, político y material. Estos rituales son concomitantes a actividades como la pesca o la caza.

Enseguida delimitaremos la continuación de nuestra argumentación. Primero se especificará el rol del chamán en su comunidad. En un segundo momento se explorarán los tipos de subjetivación que corresponden a comunidades indígenas pre-estatales. 
Michel Perrin aclara que el chamán "está allí para restablecer los desequilibrios ecológicos, climáticos, biológicos o sociales. Él no actúa por sí mismo", su comunidad le exige "que ejerza su pensamiento para vigilar al mundo y a los hombres". Igualmente él debe comunicar las causas y el desarrollo de infortunios y desarreglos. Debe también asegurar la reproducción, la abundancia y la preservación de animales para la caza. Finalmente, él debe arreglárselas para limitar al máximo los ataques de espíritus malignos. ${ }^{18}$

En la misma línea, Marcel Mauss propone que la magia debe ser comprendida en relación con la comunidad. Propone en su investigación "determinar el lugar del individuo en la magia con relación a la sociedad" y "comprender las instituciones que de allí resultan, las reglas públicas de acción y pensamiento"19

El papel del chamán en la administración de justicia es de suma importancia para la argumentación de la postura de este texto. El chamán vehicula la venganza, la autoriza. Se encarga de castigar la brujería, por ejemplo. Pero en los casos de envenenamiento y de agresión física, legitima la agresión que permite a las victimas vengarse. En efecto, esta cadena de venganzas suspende la existencia de una institución centralizada que monopolice la violencia. ${ }^{20}$ Es posible ver, entonces, que el chamán no efectúa un trabajo de transformación de sí y que tampoco es un ciudadano.

Más arriba se habló en términos muy generales acerca la vida en la ciudad de la Grecia clásica. En ella tenían lugar debates jurídicos, un debate político que comprendía el estatus de la ciudadanía, ciudadanía que implica una manera de ser, ser ciudadano. El orden jurídico es una estructura homogénea, abstracta e igualitaria; el poder y las subjetividades que dependen de él están estrechamente relacionados.

Las comunidades pre-estatales están constituidas al interior de una multiplicidad de fuentes de poder, mientras que la fuente de poder en la ciudad clásica proviene del sistema legal estatal.

Mientras el Estado pretende ser la imagen interiorizada de un orden del mundo" -en la figura del legislador, del funcionario 0 del sujeto de derecho, estas comunidades se diferencian de esa imagen en sus procesos de subjetivación, de varias maneras: por la segmentación social que los vincula en términos de alianza y filiación; por el entramado de lo humano, lo natural y lo sobrenatural donde se 'produce el sujeto', a nivel individual y colectivo; por la ausencia de un 'poder central' de carácter representativo. ${ }^{21}$

Adolfo Chaparro subraya que la política, la naturaleza, el sujeto no son reducidos a categorías meramente humanas. Se presenta una construcción ontológica que pone en escena múltiples grados y formas de poder:

Al prescindir del Estado como forma de interioridad, lo político se torna irreductible a lo puramente humano, esto es, a los consensos que se logran a través de la deliberación comunitaria 0 del contrato. Digamos que lo político adquiere otra consistencia ontológica en la medida en que pone en juego distintas fuentes de poder: animal, humano, natural, sobrehumano. ${ }^{22}$

Este autor continúa la línea de pensamiento de Deleuze y Guattari, enfatizando que

19. Mauss, M. (1995) Les fonctionnes sociales du sacré en Fuvres 1981-1985, Paris : Les Editions de Minuit, p. 26.

20. Cf. Chaumeil, J. P. (1983)Voir, savoir, pouvoir: le chamanisme chez les Yagua du Nord-est péruvien. Paris: Éditions de l'école des hautes études en sciences sociales. Se han retomado en este punto las investigaciones de Jean Pierre Chaumeil sobre los indígenas Yagua, quienes habitan en la selva amazónica entre la frontera de Perú y Brasil.

21. Chaparro Amaya, A. (2003) El diferendo entre multiculturalismo y perspectivismo. Grupo de Estudios sobre Identidad, Escuela de Ciencias Humanas, Universidad del Rosario. Revista de filosofía de la Universidad de Antioquia, Medellín, p. 11.

22. Ibíd., p. 12. 
las máquinas territoriales ${ }^{23}$ no agencian modelos, ellas favorecen el devenir, las transformaciones, los eventos colectivos, la experimentación con las máquinas de guerra.

Según el axioma formulado por Deleuze y Guattari, en la máquina territorial están activos múltiples focos de poder. En términos de procesos de subjetivación, podemos traducir este axioma diciendo que el guerrero agencia un modo de operar que le permite experimentar diversos estados y formas de saber/poder sobre el plano de inmanencia de cada cultura, esto es, sobre el territorio considerado como una totalidad habitada por diferentes tipos de seres: animales, vegetales, humanos, minerales, celestes y sobrehumanos. A pesar de este diferencial entre las voluntades de potencia, se concibe la forma de lo social como un pattern cultural compartido por hombres, animales y seres sobrenaturales en su propio proceso de subjetivación. Por eso, dentro de las máquinas territoriales los modos de subjetivación son indisociables de ese fondo de fuerzas donde se confunde la energía potencial de cada modalidad de ser y que se despliega periódicamente con ocasión del ciclo ritual, sea vital, guerrero, mágico y/0 curativo. ${ }^{24}$

Para comprender el rol del chamán, Chaparro se propone asirlo como un ser en situación. ${ }^{25}$ En este sentido se propone una pregunta: ¿Son comparables el lugar que ocupan en la sociedad el chamán y el lugar que ocupaban los filósofos griegos presocráticos?

Cada escuela filosófica propone una vida filosófica, una ética de vida. Por ejemplo la propuesta de Sócrates implica una participación activa en la polis. ${ }^{26}$ Otras escuelas le apuestan a una elección de transformación personal que no tiene como especial preocupación el devenir de la polis.
En esta medida, el rol del filósofo se discutía al interior del discurso filosófico y su elección de vida, sus comportamientos y ejercicios espirituales así lo expresaban.

Los rituales chamánicos, por otro lado, tienen la finalidad de mantener y reproducir el orden social. El chamanismo es una relación social que preserva el equilibrio entre los dioses y los hombres, así como la comunicación entre el mundo de los vivos y el de los muertos. En tanto el chamán preserva el equilibrio ecológico, biológico y social, se puede afirmar que este no actúa de manera individual. La lógica de las representaciones y prácticas chamánicas está estrechamente ligada a funciones sociales de gran importancia, como predecir las mejores condiciones para hacer la guerra o prevenir y curar las enfermedades, que en este contexto corresponden también al desequilibrio de códigos culturales, es esa lógica la enfermedad no se reduce al aspecto biológico.

He aquí un aparte de una ceremonia chamánica de curación. ${ }^{27}$ Este fragmento revela también el balance que se presenta entre el sujeto y su comunidad. En la medida en que múltiples espíritus constituyen al chamán, estos espíritus y sus conflictos hacen parte de la comunidad y deben tenerse en cuenta a la hora de administrar la misma.

\section{Nosotros, nosotros tenemos cinco} espíritus...

Ellos trabajan con la Lluvia, la Luna y el Sol.

Ellos van muy lejos, tan rápidos como la mirada...

Uno de ellos es excelente...

23. Deleuze, G y Guattari, F. (1973) L'anti-oedipe.Capitalisme et schizophrénie I, Paris : Les éditions de minuit, p. 170. "La máquina primitiva subdivide el pueblo, pero lo hace sobre una tierra indivisible en la que se inscriben relaciones conectivas, disyuntivas y conjuntivas de cada segmento con los otros. La división de la tierra efectuada en virtud de una organización administrativa, fiscal y residencial es el efecto de un primer movimiento de desterritorialización sobre las comunidades primitivas... el socius salvaje primitivo es en este la única maquina territorial en sentido estricto. Y el funcionamiento de este tipo de máquina es el siguiente: declinar alianza y filiación, declinar los linajes sobre el cuerpo de la tierra, antes de que exista un estado".

24. Ibíd., p. 14.

25. He retomado esta categoría propuesta por Jean Paul Sartre en su obra Reflexiones sobre la cuestión judía, en lo referente al lugar que poseen los sujetos según coordenadas sociales precisas. Si un sujeto aspira a una carrera chamánica lo será si hace parte de esta cosmología, no se deviene chamán leyendo a Carlos Castaneda o tomando mescalina.

26. En la medida en que para Sócrates su misión pedagógica es "útil para la ciudad -más útil que la victoria ateniense en el Olimpoporque al enseñar a la gente a ocuparse a sí misma de sí misma, le enseña a ocuparse de sí mismo con la ciudad". Foucault, M (1990) Op. Cit., p. 52.

27. Perrin, M. (1995) Poétique de seetuma, chamane guajiro, Que sais-je? Paris : Presses Universitaire de France. 
-Voy a buscar tu pequeña alma, dijo él

El va ver el alma del enfermo que quiere morir.

El la ve allá donde se encuentran los difuntos,

Allá donde se encoge la tierra por donde pasan los muertos...

-Su alma estará pronto allá, dijo él a su vez.

¡Ella ya dio media vuelta!

Ella ha vuelto a venir de allá donde se encuentra Sueño.

Porque es Sueño quien nos mata

El encierra nuestra alma cuando nos quedamos dormidos,

El la tiene prisionera.

Entonces nuestro espíritu se la quita

El la encierra en un pequeño bolso de tela,

El la mete bajo nuestro brazo.

El la cuida mucho, él la mira todo el tiempo.

Porque el alma no se queda tranquila,

Ella quisiera volver allá, muy lejos.

Este documento hace parte de una investigación efectuada por Michel Perrin sobre el pueblo Wayúu. Se quiere hacer énfasis en su constatación de una múltiple subjetividad. ${ }^{28}$ El chamán al apelar a diversos espíritus, a diversas entidades ontológicas efectúa un tipo de terapia y de curación que no busca restablecer únicamente la salud mental y biológica del paciente. Se busca restablecer el buen devenir entre los vivos y los muertos. De hecho, es difícil establecer una separación radical entre estos dos mundos. Los muertos, las plantas, los animales poseen una serie de conocimientos que son definitivos a la hora de ser un chamán. Este ser chamán es ser a la vez otros.

El problema de la conciencia, del acceso al saber de sí, del saber sobre el universo no es equivalente entre la Grecia antigua y las comunidades chamánicas. Entonces, se hace pertinente delimitar las claves epistemológicas que dirigen los ejercicios espirituales. Como ya se había dicho, dentro de la sociedad griega hay ya una escisión entre hombre y naturaleza, entre sujeto y objeto; un proceso de individualización de los sujetos, la creación de un yo, un tú, un eso exterior al sujeto. La consciencia dentro de los grupos indígenas está construida de otra forma. Castro de Viveiros presenta la noción de conciencia como una posición de sujeto que es hipostasiada en un tipo de estructura inmanente a lo humano, a lo cósmico, a lo animal..$^{29}$

En la cosmología amerindia, las ideas de cuerpo y de espíritu poseen un contenido diferente que las que existen en occidente. Los animales y los hombres comparten una condición de humanidad, la diferencia existe solamente en su forma corporal. El espíritu no es una sustancia inmaterial, es una forma reflexiva, es una subjetividad formal de almas compartida por los animales, los muertos, los hombres. El cuerpo es un crisol de afectos y de capacidades, lo que origina el punto de vista de cada ser es el cuerpo. Todos los seres comparten la condición de humanidad pero se presentan según diferentes modalidades. De esta manera, el cuerpo es el modo por el que la alteridad es percibida como tal.

Castro de Viveiros sugiere entonces el empleo del término "multinaturalismo", para explicar esta categoría conceptual, el autor propone contrastarla con las propuestas "multiculturalistas".
Mientras que estas se basan en la implicación mutua entre la unicidad de la naturaleza y la multiplicidad de las culturas -la primera garantizada por la universalidad objetiva de los cuerpos y de la sustancia, la segunda por la particularidad subjetiva de los espíritus y del significado-, la concepción amerindia supondría, por el contrario una universalidad del espíritu y una diversidad de los cuerpos. ${ }^{30}$ 
La afirmación de una universalidad del espíritu y de una diversidad de los cuerpos supone una particularidad ontológica que es clave a la hora de comprender tanto la institución chamánica como a sus ejercicios habituales: la ingestión de yage, el ayuno o el celibato. Si bien hay un conocimiento que debe ser adquirido por el chamán, este conocimiento no implica separarse del mundo exterior o controlar los afectos particulares. Porque justamente lo que cambia es la forma y estos ejercicios no estarían pensados para construir una identidad de sí propia y única como chamán, sino para restablecer, asegurar y reproducir el devenir colectivo.

Anteriormente se había dicho que no es posible aseverar que el mismo "yo" efectúa los ejercicios espirituales en Grecia y en América indígena. Incluso desde el punto de vista lingüístico se puede ver que las individualidades no son cerradas, ni homogéneas. El chamán es una posibilidad ontológica constante, cuya forma se cristaliza según acontecimientos determinados:

Siguiendo con la analogía pronominal se ve que entre el yo reflexivo de la cultura (generador del concepto de alma o espíritu) y el él con valor impersonal de la naturaleza (marcador de la relación con la alteridad corpórea), hay una posición que falta la del tú, la de la segunda persona, o el otro tomado como otro sujeto, cuyo punto de vista sirve de eco latente al del yo... Quién responde a un tú dicho por un no humano acepta la condición de ser "su segunda persona" y al asumir, a su vez, la posición del yo, lo hará ya como un no humano. (Sólo los chamanes, personas naturales por definición y oficio son capaces de circular entre las perspectivas, tuteando y siendo tuteados por las agencias extra-humanas sin perder su propia condición de sujeto). ${ }^{31}$

Las divisiones ontológicas convencionales como hombre y naturaleza, sobre las que reposa el pensamiento científico occidental son la expresión acabada de su realidad social. El concepto de naturaleza es fruto de los usos que se le han concedido en occidente.

Solamente una sociedad fundamentada sobre el trabajo de los esclavos, como lo fue por ejemplo la sociedad greco-romana, puede hablar de naturaleza en el sentido de una separación entre un mundo pleno de espíritu, aquel de los ciudadanos y un mundo que está desprovisto de espíritu, aquel de los esclavos ${ }^{32}$

$* * * * * * * * * * * * * * * *$

A manera de conclusión se puede establecer que las tramas de significación vehiculadas por las experiencias chamánicas no son comprensibles en los mismos términos que las prácticas de auto-transformación de los antiguos, porque, primeramente, en Grecia se presenta un tipo de subjetivación de individuo que se relaciona con instituciones y formas de poder que le son propias. Segundo, porque el rol del filósofo en la polis no es comparable al del chamán en su comunidad. Finalmente porque la búsqueda de la verdad para los Griegos supone de entrada la exterioridad del sujeto. Mientras que la búsqueda de conocimientos del chamán se presenta como una unidad con los espíritus, los animales, los otros hombres; además el conocimiento adquirido por el chamán opera como dispositivo del orden simbólico de las actividades de la comunidad: caza, pesca, administración de justicia, curación y prevención de enfermedades. 


\section{BIBLIOGRAFIA}

Chaparro Amaya, A. (2000) Les archives de l'ambiguïte I. Formations mythiques de savoir, Paris : Ed L'Harmattan.

\section{(2003) El diferendo entre}

multiculturalismo y perspectivismo. Grupo de Estudios sobre Identidad, escuela de Ciencias Humanas, Universidad del Rosario. Revista de filosofía de la Universidad de Antioquia, Medellín.

Chaumeil, J. P. (1983) Voir, savoir, pouvoir : le chamán isme chez les Yagua du Nord-est péruvien, Paris :Éditions de l'école des hautes études en sciences sociales.

Deleuze, G. y Guattari, F. (1972) Capitalisme et schizophrénie. L'anti- œdipe, Paris : Les Éditions de Minuit.

Foucault, M. (1984) Histoire de la sexualité, Le souci de soi, Paris : Éditions Gallimard.

----(1990) Tecnologías del yo y otros textos afines. Barcelona: Paidós.

(1999) Estética, Ética y Hermenéutica Obras esenciales III. Barcelona: Paidós.

Hadot, P. (1995) Qu'est ce -que la philosophie antique? Paris : Éditions Folio.

Lapierre, G. (2000) Le mythe de la raison, Paris : Éditions l'insomniaque.

Mauss M. (1981- 1985) Les fonctionnes sociales du sacré en Fuvres, Paris : Les Éditions de Minuit

Ortiz Pérez, L. (2004) Espacios de transgresión identitaria: relatos de la colombianidad desde los actos de desobediencia Wayúu. Grupo de identidad y diversidad, Bogotá: Centro Editorial Universidad del Rosario.

Perrin, M. (1995) Le chamanisme. Que sais-je ? Paris: Presses Universitaires de France.
Viveiros de Castro E. (1998) "Les pronoms cosmologiques et le perspectivisme amérindien". Dans Alliez, Eric (dir) Gilles Deleuze, une vie philosophique, Paris : Institut Syntélabo.

(2003) "Perspectivismo y

multinaturalismo en la América Indígena" en Racionalidad y Discurso mítico. Chaparro, A y Schumacher, C (Eds), Bogotá: Centro Editorial Universidad del Rosario/ ICAHN.

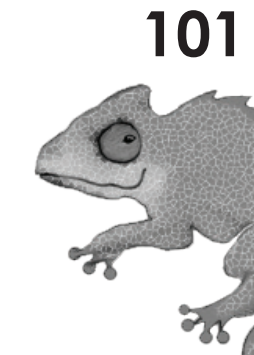

